\title{
Tobacco and oral squamous cell carcinoma: A review of carcinogenic pathways
}

\author{
Xiaoge Jiang ${ }^{1 *}$, Jiaxin Wu ${ }^{1 *}$, Jiexue Wang ${ }^{1}$, Ruijie Huang ${ }^{1}$
}

\begin{abstract}
INTRODUCTION Tobacco is one of the most important risk factors for premature death globally. More than 60 toxic chemicals in tobacco can invade the body's various systems. Oral squamous cell carcinoma (OSCC) is a pathological type of oral cancer, accounting for over $90 \%$ of oral cancers. A vast quantity of scientific, clinical and epidemiological data shows that tobacco is associated with the development of oral squamous cell carcinoma, and its carcinogenic pathways may be complicated.

METHODS We conducted a thorough electronic search by Cochrane, EMBASE and PubMed to identify relevant studies. Studies published up to the end of October 2018 were included. After assessing and selecting articles based on eligibility criteria, studies were classified and elaborated according to the pathogenesis.

RESULTS Tobacco as an important risk factor can cause epigenetic alteration of oral epithelial cells, inhibit multiple systemic immune functions of the host, and its toxic metabolites can cause oxidative stress on tissues and induce OSCG. In addition, some specific viruses such as EBV and HPV are thought to play a role in the development of OSCG.

CONCLUSIONS Oral cancer ranks eighth among the most common causes of cancerrelated deaths worldwide, and tobacco is one the most important carcinogenic factors of OSCC. This review of the literature attempts to provide directions and ideas for future related research, and emphasizes the need for efforts to reduce tobacco consumption.
\end{abstract}

\author{
AFFILIATION \\ 1 Department of Pediatric \\ Dentistry, State Key \\ Laboratory of Oral Diseases, \\ National Clinical Research \\ Center for Oral Diseases, \\ West China Hospital of \\ Stomatology, Sichuan \\ University, Chengdu, China \\ *Contributed equally \\ CORRESPONDENCE TO \\ Ruijie Huang. Department \\ of Pediatric Dentistry, State \\ Key Laboratory of Oral \\ Diseases, National Clinical \\ Research Center for Oral \\ Diseases, West China Hospital \\ of Stomatology, Sichuan \\ University, Chengdu, China. \\ E-mail: ruijmhuang@gmail.com \\ ORCID ID: https://orcid. \\ org/0000-0003-3211-518X \\ KEYWORDS \\ tobacco, smoking, oral \\ squamous cell carcinoma, \\ carcinogenic pathways
}

Received: 28 December 2018 Revised: 18 February 2019 Accepted: 20 March 2019

\section{INTRODUCTION}

It is well known that tobacco is one of the most important risk factors for premature death globally ${ }^{1}$. It is reported that there are more than 1.3 billion smokers worldwide ${ }^{2}$. The World Health Organization (WHO) estimates that tobacco causes nearly 6.4 million deaths and hundreds of billions of dollars of economic damage worldwide each year ${ }^{3}$. If current trends continue, by 2030 tobacco will kill more than 8 million people worldwide each year, most of which will occur in developing countries with lower incomes ${ }^{4}$. Although many people are aware that tobacco harms their health, most still accept smoking as part of their daily life, unaware that more than 60 toxic chemicals including carcinogens and cancerpromoting substances ${ }^{5,6}$, in tobacco can invade the body's various systems ${ }^{7}$. Each cigarette is made of many ingredients, and some tobacco companies may use certain flavor additives to make their tobacco products more attractive, which may also be harmful to health ${ }^{8}$. Not only can these original components cause harm, but the intermediate metabolites play an unavoidable role in the process during smoking.

Oral squamous cell carcinoma (OSCG) is a 
pathological type of oral cancer, accounting for over $90 \%$ of oral cancers ${ }^{9}$. Oral cancer ranks eighth among the most common causes of cancer-related deaths worldwide ${ }^{10}$. Oral and oropharyngeal cancers are reported to account for approximately 220000 new cases per year ( $5 \%$ of all cancers) worldwide ${ }^{11}$. According to the recent epidemiology of OSCG, the incidence in lower/middle income countries or developing countries tends to be higher than that of developed countries ${ }^{12}$. The data show that the risk factors that attribute to OSCC are age, sex, race, gender, tobacco, alcohol, betel nut, diet and nutrition ${ }^{13}$. Among them the most common is tobacco. Many epidemiological studies have demonstrated a clear dose-response relationship between tobacco use and the risk of oral cancer or potentially malignant oral disease. Early in 1994, a study ${ }^{14}$ analyzed 454 patients with oral carcinoma and found that $60 \%$ of those with oral carcinoma smoked and over 95\% of neoplasms were squamous cell carcinoma, while another study ${ }^{15}$ in 1999 stressed the significance of tobacco in the progress of oral epithelial dysplasia (OED) in a large number of European patients.

More than 180000 cases of oral cancer occur every year in South-East Asia; approximately $90 \%$ of which are due to smoking and chewing habits. Depending on the different products, tobacco may contain more than 60 established or potential carcinogens that can increase the relative risk of cancer through different mechanisms, including oxidative stress on tissues, persistent reactive oxygen species, lipids, carbohydrates and DNA to disrupt cell cycle-regulated mutations or through effects on the immune system ${ }^{16}$.

It is widely accepted that tobacco is one the most important carcinogenic factors of OSCG, and its carcinogenic pathways may be multifaceted. The purpose of this review is to summarize the possible mechanisms of tobacco that promote the development of OSCG, on the basis of relevant research, so as to provide directions and ideas for future related research.

\section{METHODS}

\section{Eligibility criteria}

The eligibility criteria for studies were: 1) research articles that studied the pathogenesis of oral squamous cell carcinoma (SCC) caused by smoking, and 2) articles in English. Epidemiological investigations, reports, literature reviews, comments and letters to the editor were excluded.

\section{Search strategy and studies selection}

We conducted a thorough electronic search by Cochrane, EMBASE and PubMed to identify relevant studies. Studies published up to the beginning of December 2018 were included. The search terms were: [Mouth Neoplasms OR Oral carcinoma OR Oral squamous cell carcinoma OR Oral Sprays OR OSCG] AND [Tobacco OR Smoking OR Tobacco Products OR Tobacco smoking OR Cigarette OR Cigarette smoking OR Cigar]. No data restrictions were applied in searching.

\section{RESULTS}

We first excluded duplicate articles. Then, two authors independently assessed the titles and abstracts of the studies on the basis of the theme of this review. Next, the full text of the remaining studies was evaluated and articles without conclusions of pathogenesis were excluded. Finally, studies were classified and elaborated according to the pathogenesis. When the two authors' opinions were not uniform, consensus was reached through discussion along the process (Figure 1).

\section{DISCUSSION}

\section{Possible carcinogenic pathways}

The possible carcinogenic pathways are summarized in Figure 2.

Figure 1. Flow chart of studies selection process

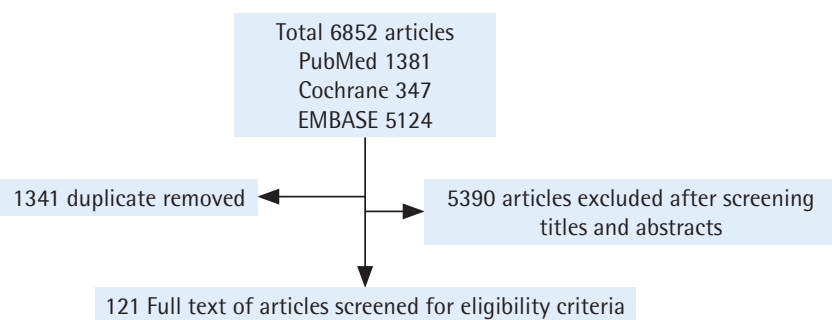

121 Full text of articles screened for eligibility criteria

89 articles were excluded 21 review

45 epidemiological investigation 23 not included pathogenic mechanism

articles included in this review

$\downarrow$

13 Epigenetic alteration of oral epithelial cells

5 Inhibit multiple systemic immune functions 6 0xidative stress alterations

8 Possible cooperation between tobacco and the Epstein-Barr virus (EBV) in OSCC 
Figure 2. The possible carcinogenic pathways

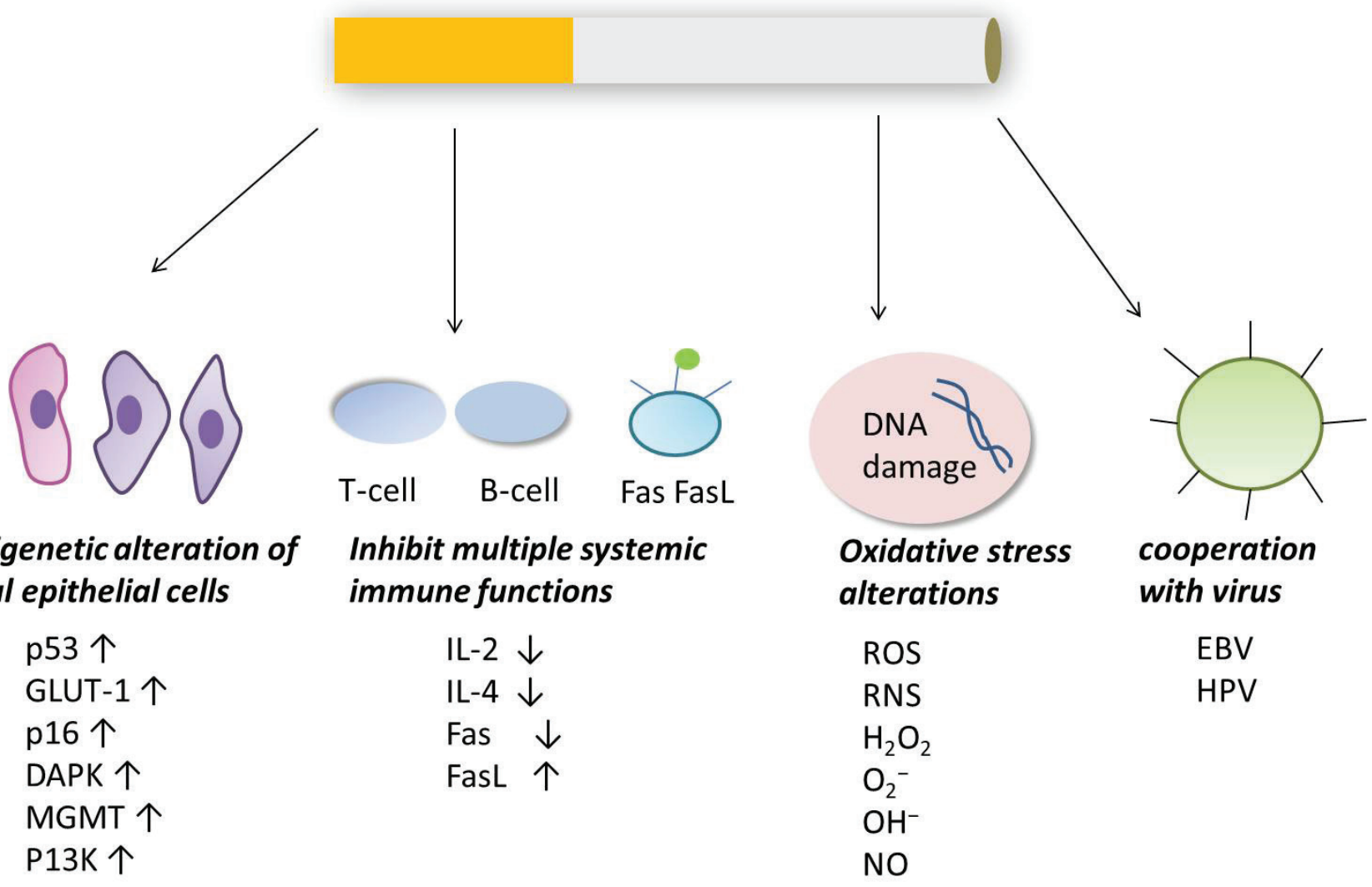

Epigenetic alteration of oral epithelial cells

Many studies have shown that tobacco can cause the abnormal expression of p53, GLUT-1, p16, DAPK, MGMT, P13K and other genes in oral epithelium, which is associated with the occurrence of OSCG.

The p53 cancer suppressor gene is the most universally identified mutated gene in human malignancies. The protein encoded by it is a transcriptional factor that controls the start of the cell cycle ${ }^{17}$. The p53-mediated cellular signal transduction pathway plays an important role in regulating normal cell life activities. After mutation, the p53 gene loses its regulatory effects on cell growth, apoptosis and DNA repair, and transforms from a tumor suppressor gene into an oncogene ${ }^{18}$. In $1994^{19}$, a study in India investigated the expression of p53 protein in premalignant oral lesions and observed that p53 aberrations are an inchoate change in the development of oral carcinoma. They found that the proportion of p53 protein overexpression was high in premalignant and malignant oral lesions in patients who were heavily consuming tobacco. Later, further studies ${ }^{20-23}$ verified that tobacco was associated with the overexpression of the p53 gene in epithelial cells.

Glucose transporters (GLUTs) are a protein family that mediates glucose transport through the cell membrane. Glucose metabolism depends on the uptake of glucose by cells. However, glucose cannot freely enter cells through the lipid bilayer structure of the cell membrane. Glucose uptake by cells requires glucose transporters on the cell membrane. The expression of GLUT-1 is upregulated in malignant cells, which suggests increased proliferative activity, energy requirements, aggressive behaviour and poor radiation response ${ }^{24}$. GLUT-1 expression correlates significantly with histological grade and pathology Tumor Node Metastasis (pTNM) staging of OSCC ${ }^{25-27}$. A recent study showed that GLUT-1 significantly correlates with tobacco-related human oral carcinoma ${ }^{28}$. In that study, involving 50 samples, the tobacco addiction group showed a larger proportion of cells displaying GLUT-1 immunostaining (79.2\%) compared with the non-tobacco group (52\%), which was statistically significant. 
In addition, p16 (MTS, multiple tumor suppressor 1), DAPK (death-associated protein kinase), MGMT (O6-methylguanine-DNA methyltransferase), PI3K (the phosphatidylinositol 3-kinase), c-myc and other genes were investigated in oral tobacco-related tumor tissues and cancer associated adjacent tissues ${ }^{21,29-32}$. The epigenetic alteration of these genes is a common event in oral malignancy, and is an inchoate change discovered in oral mucosa of these patients. It indicates that epigenetic alteration is of vital importance in tobacco associated oral carcinogenesis. To validate the findings, further studies are needed that comprise larger sample sizes.

\section{Inhibition of multiple systemic immune functions}

Immune dysfunction plays an important role in the escape of cancer cells from effector immunological functions, leading to the occurrence, establishment and development of the cancer. The incidence of malignancy in immunocompromised patients is 100 times higher than in normal ones ${ }^{33}$.

IL-4 is an anti-inflammatory cytokine and various in vitro studies have documented its anti-tumor activity on breast and colon cancer ${ }^{34}$. It directly modulates proliferation of various cancer cell types including gastric and renal cancers by increasing expression of p21WAFI and interferon regulating factor (IRF-1) and decreasing cyclin-dependent kinase (CDK)-2 activities besides facilitating the infiltration of inflammatory cells such as macrophages, eosinophils, and neutrophils ${ }^{35}$. A study ${ }^{36}$ in 2010 investigated the systemic immunity and the expression of IL-4 and IL-2 in T-cell subsets from peripheral blood of tobacco-related OSCC patients, on the basis of major lymphocyte subsets. They found that those with oral malignancy showed obviously decreased CD4+ and CD3+ T-cell subsets with a lower CD4/ CD8 percentage in comparison to the normal controls. The proportion of CD4+ IL-2+ was obviously lower while CD8+ IL-4+ and CD3+ IL-4+ T cells were significantly higher in them in comparison to the normal controls. Decreased expression of IL-2 in both CD8+ and CD4+ subsets was connected with the late stage of the neoplasm. The tobacco-related oral cancer is likely to be connected with multiple systemic immune impairs, especially defected CD4+ and CD3+ T cells and a differential regulation of IL-4 and IL-2 in CD8+ and CD4+ T-cell subsets in the peripheral blood. In addition, some scientists assessed the relationship between IL-4 promoter and IL-6 functional genetic polymorphisms in Asian Indians and tobacco-related oral cancer. In the study ${ }^{37}$, IL-4 genotype seemed to be susceptible in patients, while IL-6 genotype seemed to be protective. It is suggested that tobacco can decrease the transcription rate of IL-4 gene as this may have anti-tumor effects.

Fas receptor and Fas Ligand (FasL) system are associated with the suppression of apoptosis, insensitivity to chemotherapy, and with providing immune privilege to a majority of the tumours via the Fas mediated apoptosis of tumour-specific lymphocytes ${ }^{38-40}$. The decreased expression of Fas and/or increased expression of FasL avails tumour transformation and malignant progression ${ }^{41}$. A study ${ }^{42}$ in 2011 used DNA flow cytometry for cell cycle parameters and immunohistochemistry for Fas and FasL on 10 normal samples and 41 paraffin embedded tumours. The results showed that low Fas expression was observed only in 2 of 41 (5\%) oral tumours while FasL immunoreactivity was observed in 26 of 41 (63.4\%) tumours on the cell membrane. In contrast, all 10 normal oral tissues performed strong cytoplasmic and membrane Fas receptor immunoreactivity but without FasL staining. Up-regulation of FasL and downregulation of Fas receptor is likely to be an important character of tobacco-related OSCC.

From the above, the immunosuppressive effects may exist in tobacco-related OSCG. The IL-4 promoter and IL-6 functional genetic polymorphisms, Fas and FasL system etc. are supposed to be used as important prognostic variables in tobacco-related OSCG patients. Further, the IL-1 $\beta-511 \mathrm{C} / \mathrm{T}$ polymorphism ${ }^{43}$, interferon(IFN) ${ }^{44}$ may also play a role. Future studies that include larger sample sizes are needed to validate these findings.

\section{Oxidative stress alterations}

Tobacco, which is a foreign substance ${ }^{45}$, has been shown to stimulate ${ }^{46}$ the body to produce more free radicals that are endogenously produced in various cellular metabolic activities and which play a role in preventing microbial pathogen invasion at low concentrations. However, as their concentration rises, they may damage cellular components, ultimately leading to denaturation or mutation, which can be seen in parasitic infections, inflammatory diseases 
and cancers ${ }^{47}$. It has been proven that oral cancer is related to oxidative stress ${ }^{48,49}$. Free radicals include reactive oxygen species (ROS), reactive nitrogen species (RNS) and reactive oxygen metabolites such as hydrogen peroxide $\left(\mathrm{H}_{2} \mathrm{O}_{2}\right)$, superoxide anions (O2-), hydroxyl radicals ( $\mathrm{OH}-)$, nitric oxide (NO) and malondialdehyde. They can induce several DNA damages including strand breakage, DNA-protein cross-linkage and base modification. They can form lipid peroxides and react with cell membrane fatty $\operatorname{acids}^{45}$. For instance, ROS and RNS participates in the initiation and promotion of carcinogenesis through DNA damage ${ }^{50,51}$. NO-mediated base excision inhibits DNA repair, which may aggravate oxidative DNA damage in cells, which is possibly related to carcinogenesis $^{52,53}$. They can also affect antioxidant systems. For example, GSH ${ }^{54}$ levels are a key factor in protecting organisms from toxicity and disease, as they provide reduced power for several reactions and play an important role in the detoxification of hydrogen peroxide and other free radicals. Higher oxidants and lower antioxidant activities in blood of cancer cases suggest their importance in progression of disease $\mathrm{e}^{55,56}$. They can also decrease the normal effects of the superoxide dismutase (SOD).

A study ${ }^{57}$ in 2005 researched tobacco habits and alterations in enzymatic antioxidant system in oral cancer. They found that the risk of oral cancer development in smokers was significantly higher than non-smokers on the basis of erythrocytic glutathione reductase (GR), SOD, catalase (CAT) and plasma thiol. In addition, updated studies ${ }^{58-62}$ have proven the association between tobacco related OSCC and oxidative stress alterations. More research is needed to validate these findings.

Possible cooperation between tobacco and the EpsteinBarr virus (EBV) in OSCC

Epstein-Barr virus (EBV), also known as human herpes virus $4(\mathrm{HHV}-4)^{63}$, is a type of herpes virus ${ }^{64}$. EBV causes lifelong persistent infections in more than $90 \%$ of the world's population. The virus has an incubation period in healthy individuals carrying the virus. Under ambient pressure, the virus can be reactivated periodically during the lifetime of the individual. EBV is often associated with a variety of malignancies such as Burkitt's lymphoma, Hodgkin's disease, stomach cancer, and nasopharyngeal carcinoma (NPG) ${ }^{65}$.
Tobacco is an important risk factor, which through its toxic metabolites, can cause DNA damage that induces OSCG. In addition, some specific viruses are thought to play a role in the development of OSCG $^{66}$. For example, a study showed that there is a possible interaction between tobacco and HPV16 in inducing $\mathrm{OSCC}^{67}$. Some published controlled studies provide indirect evidence of a significant epidemiological association between EBV and OSCG ${ }^{68}$. Furthermore, several EBV proteins have been found to be expressed in OSCC tissues and are associated with tumor phenotypes ${ }^{69}$, which indicates that there is a strong correlation between EBV and OSCC. As mentioned above, the relevant pathogenesis of NPC is similar. Some authors have noticed the association between tobacco and EBV through epidemiological investigations, and they believe that tobacco may play a role in the carcinogenesis of NPC by inducing EBV reactivation. In a study ${ }^{70}$ in the Guangdong province of China, it was shown that cigarette smoke extract (CSE) promotes EBV replication in Akata and B95-8 cells and enhances the expression of the EBV transcriptional factors, Zta and Rta, which may be the latent-to-lytic switch of EBV. It confirmed that tobacco may act as an inducer of recurrent EBV reactivation ${ }^{71}$, which has been shown to promote genome instability and enhance NPC progression. However, few studies have mentioned the interaction of EBV and tobacco in the development of OSCG ${ }^{72}$, or in other words, provided sufficient evidence to explain the relationship between them. The results of one study showed that in OSCG patients, the difference in EBV prevalence between the smoking control group and the non-smoking control group was not significant. We believe that EBV is present in oral diseases such as OSCC and OLP. Smoking, drinking or age does not appear to be a risk factor for EBV infection. However, another study in Yemen ${ }^{73}$ showed a strong correlation between the rate of exposure to shama (tobacco) and the positive rate of EBV in OSCG patients. This has never been reported before. In conclusion, it can be assumed that tobacco induces the occurrence of OSCG by inducing EBV reactivation, similar to NCP. This carcinogenic pathway may be another potential mechanism. Further epidemiological and experimental studies are necessary to confirm the interaction between tobacco use and EBV positivity in oral cancer and to reveal potential mechanisms. 


\section{CONCLUSIONS}

It has been proven that the use of tobacco is associated with the development of OSCC. Based on existing research, tobacco can cause epigenetic alteration of oral epithelial cells, inhibit multiple systemic immune functions of the host, and through its toxic metabolites cause oxidative stress on tissues to induce OSCC. In addition, some specific viruses such as EBV and HPV are thought to play a role in the development of OSCC. To validate these findings, further studies are needed comprising larger sample sizes. Meanwhile, with the development of research on this topic, more possible mechanisms remain to be studied. As the treatment of OSCC is difficult and the prognosis is poor, further research on this topic will be helpful for early diagnosis or prevention of tobacco-related oral carcinoma through efforts for cessation of tobacco consumption.

\section{REFERENCES}

1. Smoking prevalence and attributable disease burden in 195 countries and territories, 1990-2015: a systematic analysis from the Global Burden of Disease Study 2015. The Lancet. 2017;389(10082):1885-1906. doi:10.1016/S0140-6736(17)30819-X

2. Walt G. WHO's World Health Report 2003: Shaping the future depends on strengthening health systems. Bmj British Medical Journal. 2004;328(7430):6. doi:10.1136/bmj.328.7430.6

3. Samim D, Méan M, Clair C, Marques-Vidal P. A 10-year observational study on the trends and determinants of smoking status. PLoS One. 2018;13(7):e0200010. doi:10.1371/journal.pone.0200010

4. Cederbye F, Norberg R. WHO Report on the Global Tobacco Epidemic 2011: Warning about the dangers of tobacco. Geneva, Switzerland: World Health Organization. 2008;34(3):581-581. https://www.who.int/tobacco/ global_report/2011/en/. Accessed December 28, 2018.

5. Ezzati M, Lopez AD. Estimates of global mortality attributable to smoking in 2000. Lancet. 2003;362(9387):847-852. doi:10.1016/S0140-6736(03)14338-3

6. Roe FJC. Role of 3,4-Benzopyrene in Carcinogenesis by Tobacco Smoke Condensate. Nature. 1962;194(4833):1089-1090. doi:10.1038/1941089a0

7. Proctor RN. The Global Smoking Epidemic: A History and Status Report. Clin Lung Cancer. 2004;5(6):371-376. doi:10.3816/clc.2004.n.016

8. Lisko JG, Stanfill SB, Watson CH. Quantitation of ten flavor compounds in unburned tobacco products. Anal Methods. 2014;6(13):4698-4704. doi:10.1039/C4AY00271G

9. Johnson NW, Jayasekara P, Amarasinghe AA. Squamous cell carcinoma and precursor lesions of the oral cavity: epidemiology and aetiology. Periodontol. 2011;57(1):1937. doi:10.1111/j.1600-0757.2011.00401.x

10. Patel RS, Clark JR, Dirven R, Wyten R, Gao K, O’Brien CJ. Prognostic factors in the surgical treatment of patients with oral carcinoma. ANZ J Surg. 2010;79(1-2):19-22. doi:10.1111/j.1445-2197.2008.04791.x

11. Abram MH, van Heerden WF, Rheeder P, Girdler-Brown BV, van Zyl AW. Epidemiology of oral squamous cell carcinoma. SADJ. 2012;67(10):550-553. https://www. ncbi.nlm.nih.gov/pubmed/?term $=23957093$. Accessed December 28, 2018.

12. Warnakulasuriya S. Global epidemiology of oral and oropharyngeal cancer. Oral Oncol. 2009;45(4-5):309316. doi:10.1016/j.oraloncology.2008.06.002

13. McDowell JD. An Overview of Epidemiology and Common Risk Factors for Oral Squamous Cell Carcinoma. Otolaryngol Clin North Am. 2006;39(2):277-294. doi:10.1016/j.otc.2005.11.012

14. Llewelyn J, Mitchell R. Smoking, alcohol and oral cancer in south east Scotland: a 10-year experience. Br J Oral Maxillofac Surg. 1994;32(3):146-152. doi:10.1016/0266-4356(94)90098-1

15. Jaber MA, Porter SR, Gilthorpe MS, et al. Risk factors for oral epithelial dysplasia--the role of smoking and alcohol. Oral Oncol. 1999;35(2):151-156. doi:10.1016/S1368-8375(98)00106-7

16. Yuan JM, Yuan JM, Stepanov I, et al. Abstract 4347: A randomized phase 2 clinical trial of PEITC on detoxification of tobacco-specific and non-specific carcinogens and toxicants. Cancer Research. 2016;76(Suppl 14):43474347. doi:10.1158/1538-7445.AM2016-4347

17. Fischer M, Quaas M, Steiner L, Engeland K. The p53p21-DREAM-CDE/CHR pathway regulates G2/M cell cycle genes. Nucleic Acids Res. 2016;44(1):164-174. doi:10.1093/nar/gkv927

18. Williams AB, Schumacher B. p53 in the DNA-DamageRepair Process. Cold Spring Harb Perspect Med. 2016;6(5):a026070. doi:10.1101/cshperspect.a026070

19. Kaur J, Srivastava A, Ralhan R. Overexpression of p53 protein in betel- and tobacco-related human oral dysplasia and squamous-cell carcinoma in India. Int J Cancer. 1994;58(3):340-345. doi:10.1002/ijc.2910580305

20. Baral R, Patnaik S, Das BR. Co-overexpression of p53 and c-myc proteins linked with advanced stages of beteland tobacco-related oral squamous cell carcinomas from eastern India. Eur J Oral Sci. 2010;106(5):907-913. doi:10.1046/j.0909-8836.1998.eos106502.x

21. Wong YK, Liu TY, Chang KW, Lin SC, Chao TW, Li PL, Chang CS. p53 alterations in betel quid- and tobacco-associated oral squamous cell carcinomas from Taiwan. J Oral Pathol Med. 2010;27(6):243-248. doi:10.1111/j.1600-0714.1998.tb01950.x

22. Chakrobarty B, Roy JG, Majumdar S, Uppala D. Relationship among tobacco habits, human papilloma virus 
(HPV) infection, p53 polymorphism/mutation and the risk of oral squamous cell carcinoma. J Oral Maxillofac Pathol. 2014;18(2):211-216. doi:10.4103/0973-029X.140752

23. Xu J, Gimenezconti IB, Cunningham JE, et al. Alterations of p53, cyclin D1, Rb, and H-ras in human oral carcinomas related to tobacco use. Cancer. 2015;83(2):204-212. doi:10.1002/(SICI) 1097 0142(19980715)83:2<204::AID-CNCR2>3.0.CO;2-Q

24. Azad N, Kumari Maurya M, Kar M, et al. Expression of GLUT-1 in oral squamous cell carcinoma in tobacco and non-tobacco users. J Oral Biol Craniofac Res. 2016;6(1):25-31. doi:10.1016/j.jobcr.2015.12.006

25. Sikdar N, Paul RR, Roy B. Glutathione S-transferase M3 (A/A) genotype as a risk factor for oral cancer and leukoplakia among Indian tobacco smokers. Int J Cancer. 2004;109(1):95-101. doi:10.1002/ijc.11610

26. Harshani JM, Yeluri S, Guttikonda VR. Glut-1 as a prognostic biomarker in oral squamous cell carcinoma. J Oral Maxillofac Pathol. 2014;18(3):372-378. doi:10.4103/0973-029X.151318

27. Li CX, Sun JL, Gong ZC, et al. Prognostic value of GLUT-1 expression in oral squamous cell carcinoma: A prisma-compliant meta-analysis. Medicine (Baltimore). 2016;95(45):e5324. doi:10.1097/md.0000000000005324

28. Azad N, Kumari MM, Kar M, et al. Expression of GLUT1 in oral squamous cell carcinoma in tobacco and nontobacco users. J Oral Biol Craniofac Res. 2016;6(1):2531. doi:10.1016/j.jobcr.2015.12.006

29. Kulkarni V, Saranath D. Concurrent hypermethylation of multiple regulatory genes in chewing tobacco associated oral squamous cell carcinomas and adjacent normal tissues. Oral Oncol. 2004;40(2):145-153. doi:10.1016/S1368-8375(03)00143-X

30. Garg R, Kapoor V, Mittal M, Singh MK, Shukla NK, Das $\mathrm{SN}$. Abnormal expression of PI3K isoforms in patients with tobacco-related oral squamous cell carcinoma. Clin Chim Acta. 2013;416:100-106. doi:10.1016/j.cca.2012.11.027

31. Smitha T, Mohan CV, Hemavathy S. Prevalence of human papillomavirus16 DNA and p16INK4aprotein in oral squamous cell carcinoma: A systematic review and metaanalysis. J Oral Maxillofac Pathol. 2017;21(1):76-81. doi:10.4103/jomfp.JOMFP_248_16

32. Chakrabarti S, Multani S, Dabholkar J, Saranath D. Whole genome expression profiling in chewing-tobaccoassociated oral cancers: a pilot study. Med Oncol. 2015;32(3):60. doi:10.1007/s12032-015-0483-4

33. Kersey JH, Spector BD, Good RA. Primary immunodeficiency diseases and cancer: the immunodeficiency-cancer registry. Int J Cancer. 2010;12(2):333-347. doi:10.1002/ijc.2910120204

34. Toi M, Bicknell R, Harris AL. Inhibition of colon and breast carcinoma cell growth by interleukin-4. Cancer. 1992;52(2):275-279. doi:10.1002/1097-0142(19920115)69:2<603::AIDCNCR2820690256>3.0.CO;2
35. Yu SJ, Kim HS, Cho SW, Sohn J. IL-4 inhibits proliferation of renal carcinoma cells by increasing the expression of p21WAF1 and IRF-1. Exp Mol Med. 2004;36(4):372-379. doi:10.1038/emm.2004.49

36. Manchanda P, Sharma SC, Das SN. Differential regulation of IL-2 and IL-4 in patients with tobacco-related oral squamous cell carcinoma. Oral Dis. 2010;12(5):455-462. doi:10.1111/j.1601-0825.2005.01220.x

37. Gaur P, Mittal M, Mohanti BK, Das SN. Functional variants of IL4 and IL6 genes and risk of tobacco-related oral carcinoma in high-risk Asian Indians. Oral Dis. 2011;17(7):720-726. doi:10.1111/j.1601-0825.2011.01831.x

38. Hahne M, Rimoldi D, Schroter M, et al. Melanoma Cell Expression of Fas(Apo-1/CD95) Ligand: Implications for Tumor Immune Escape. Science. 1996;274(5291):13631366. doi:10.1126/science.274.5291.1363

39. O’Connell J, O'Sullivan GC, Collins JK, Shanahan F. The Fas counterattack: Fas-mediated T cell killing by colon cancer cells expressing Fas ligand. J Exp Med. 1996;184(3):1075-1082. doi:10.1084/jem.184.3.1075

40. Reichmann E. The biological role of the Fas/FasL system during tumor formation and progression. Semin Cancer Biol. 2002;12(4):309-315. doi:10.1016/S1044-579X(02)00017-2

41. Müschen M, Warskulat U, Beckmann MW. Defining CD95 as a tumor suppressor gene. J Mol Med. 2000;78(6):312325. doi:10.1007/s001090000112

42. Das SN, Khare P, Singh MK, Sharma SC. Fas receptor (CD95) \& Fas ligand (CD178) expression in patients with tobacco-related intraoral squamous cell carcinoma. Indian J Med Res. 2011;134(1):54-60. https://www.ncbi.nlm. nih.gov/pmc/articles/PMC3171918/. Accessed December $28,2018$.

43. Lakhanpal M, Yadav DS, Devi TR, et al. Association of interleukin- $1 \beta-511 \mathrm{C} / \mathrm{T}$ polymorphism with tobaccoassociated cancer in northeast India: a study on oral and gastric cancer. Cancer Genet. 2014;207(1-2):1-11. doi:10.1016/j.cancergen.2014.01.002

44. Agarwal A, Rani M, Saha GK, Valarmathi TM, Bahadur S, Mohanti BK, Das Satya N. Disregulated expression of the Th2 cytokine gene in patients with intraoral squamous cell carcinoma. Immunol Invest. 2003;32(1-2):17. doi:10.1081/IMM-120019205

45. Zhao YH, Zhang M, Yan F, Casto BC, Tang XF. Nicotineinduced upregulation of antioxidant protein Prx 1 in oral squamous cell carcinoma. Chin Sci Bull. 2013;58(16):19121918. doi:10.1007/s11434-013-5779-1

46. Peterson LA. Formation, Repair, and Genotoxic Properties of Bulky DNA Adducts Formed from Tobacco-Specific Nitrosamines. J Nucleic Acids. 2010;2010(14):284935. doi:10.4061/2010/284935

47. Kumar A, Pant MC, Singh HS, Khandelwal S. Assessment of the redox profile and oxidative DNA damage $(8-\mathrm{OHdG})$ in squamous cell carcinoma of head and neck. J Cancer Res Ther. 2012;8(2):254-259. 
doi:10.4103/0973-1482.98980

48. Srivastava KC, Austin RD, Shrivastava D. Evaluation of oxidant-antioxidant status in tissue samples in oral cancer: A case control study. Dent Res J. 2016;13(2):181-187. doi:10.4103/1735-3327.178210

49. Patel BP, Rawal UM, Dave TK, et al. Lipid Peroxidation, Total Antioxidant Status, and Total Thiol Levels Predict Overall Survival in Patients With Oral Squamous Cell Carcinoma. Integr Cancer Ther. 2007;6(4):365-372. doi:10.1177/1534735407309760

50. Korde SD, Basak A, Chaudhary M, Goyal M, Vagga A. Enhanced Nitrosative and Oxidative Stress with Decreased Total Antioxidant Capacity in Patients with Oral Precancer and Oral Squamous Cell Carcinoma. Oncology. 2011;80(5-6):382-389. doi:10.1159/000329811

51. Lin WJ, Jiang RS, Wu SH, Chen FJ, Liu SA. Smoking, alcohol, and betel quid and oral cancer: a prospective cohort study. J Oncol. 2011;2011:525976. doi:10.1155/2011/525976

52. Patel JB, Shah FD, Shukla SN, Shah PM, Patel PS. Role of nitric oxide and antioxidant enzymes in the pathogenesis of oral cancer. J Cancer Res Ther. 2009;5(4):247-253. doi:10.4103/0973-1482.59898

53. Beevi SS, Rasheed AM, Geetha A. Evaluation of oxidative stress and nitric oxide levels in patients with oral cavity cancer. Jpn J Clin Oncol. 2004;34(7):379-385. doi:10.1093/jjco/hyh058

54. Fiaschi AI, Cozzolino A, Ruggiero G, Giorgi G. Glutathione, ascorbic acid and antioxidant enzymes in the tumor tissue and blood of patients with oral squamous cell carcinoma. Eur Rev Med Pharmacol Sci. 2005;9(6):361367. PMID:16479741.

55. Bhagat SS, Ghone RA, Suryakar AN, Hundekar PS. Lipid peroxidation and antioxidant vitamin status in colorectal cancer patients. Indian J Physiol Pharmacol. 2011;55(1):72-76. PMID:22315813.

56. Battisti V, Maders LD, Bagatini MD, et al. Oxidative stress and antioxidant status in prostate cancer patients: relation to Gleason score, treatment and bone metastasis. Biomed Pharmacother. 2011;65(7):516-524. doi:10.1016/j.biopha.2011.06.003

57. Patel BP, Rawal UM, Shah PM, Prajapati JA, Rawal RM, Dave TK, Patel PS. Study of Tobacco Habits and Alterations in Enzymatic Antioxidant System in Oral Cancer. Oncology. 2005;68(4-6):511-519. doi:10.1159/000086995

58. Yadav DS, Chattopadhyay I, Verma A. A pilot study evaluating genetic alterations that drive tobaccoand betel quid-associated oral cancer in Northeast India. Tumour Biol. 2014;35(9):9317-9330. doi:10.1007/s13277-014-2222-4

59. Srivastava KC, Austin RD, Shrivastava D, Sethupathy S, Rajesh S. A Case control study to evaluate oxidative stress in plasma samples of oral malignancy. Contemp Clin Dent. 2012;3(3):271-276. doi:10.4103/0976-237X.103617

60. Elena B, Galina Z, Svetlana G, et al. Biomarkers of oxidative stress and smoking in cancer patients. J Cancer Res Ther. 2010;6(1):47-53. doi:10.4103/0973-1482.63569

61. Patel BP, Rawal UM, Rawal RM, Shukla SN, Patel PS. Tobacco, Antioxidant Enzymes, Oxidative Stress, and Genetic Susceptibility in Oral Cancer. Am J Clin Oncol. 2008;31(5):454-459. doi:10.1097/coc.0b013e31816a61da

62. Srivastava KC, Austin RD, Shrivastava D. Evaluation of oxidant-antioxidant status in tissue samples in oral cancer: A case control study. Dent Res J. 2016;13(2):181-187. doi:10.4103/1735-3327.178210

63. Metgud R, Astekar M, Verma M, Sharma A. Role of viruses in oral squamous cell carcinoma. Oncology Reviews. 2012;6(2):164-170. doi:10.4081/oncol.2012.e21

64. Andersson J. An Overview of Epstein-Barr Virus: from Discovery to Future Directions for Treatment and Prevention. Herpes. 2000;7(3):76-82. PMID:11867007.

65. Shimakage M, Horii K, Tempaku A, Kakudo K, Shirasaka T, Sasagawa T. Association of Epstein-Barr virus with oral cancers. Hum Pathol. 2002;33(6):608-614. doi:10.1053/hupa.2002.129786

66. Jalouli J, Jalouli MM, Sapkota D, Ibrahim SO, Larsson PA, Sand L. Human papilloma virus, herpes simplex virus and epstein barr virus in oral squamous cell carcinoma from eight different countries.Anticancer Res. 2012;32(2):571580. http://ar.iiarjournals.org/content/32/2/571.long. Accessed December 28, 2018.

67. Polz-Gruszka D, Morshed K, Stec A, Polz-Dacewicz M. Prevalence of Human papillomavirus (HPV) and EpsteinBarr virus (EBV) in oral and oropharyngeal squamous cell carcinoma in south-eastern Poland. Infect Agent Cancer. 2015;10(1):37-44. doi:10.1186/s13027-015-0031-z

68. Kobayashi I, Shima K, Saito I, et al. Prevalence of Epstein-Barr virus in oral squamous cell carcinoma. J Pathol. 1999;189(1):34-39. doi:10.1002/(SICI)10969896(199909)189:1<34::AID-PATH391>3.0.CO;2-4

69. Yen CY, Lu MC, Tzeng CC, et al. Detection of EBV Infection and Gene Expression in Oral Cancer from Patients in Taiwan by Microarray Analysis. Biomed Res Int. 2009;2009:1-15. doi:10.1155/2009/904589

70. Xu FH, Xiong D, Xu YF, et al. An Epidemiological and Molecular Study of the Relationship Between Smoking, Risk of Nasopharyngeal Carcinoma, and Epstein-Barr Virus Activation. J Natl Cancer Inst. 2012;104(18):13961410. doi:10.1093/jnci/djs320

71. Fang C, Lee CC, Chang Y, et al. Recurrent chemical reactivations of $\mathrm{EBV}$ promotes genome instability and enhances tumor progression of nasopharyngeal carcinoma cells. Int J Cancer. 2010;124(9):2016-2025. doi:10.1002/ijc.24179

72. Higa M, Kinjo T, Kamiyama K, Chinen K, Iwamasa T, Arasaki A, Sunakawa H. Epstein-Barr virus (EBV)-related oral squamous cell carcinoma in Okinawa, a subtropical island, in southern Japan--simultaneously infected with human papillomavirus (HPV). Oral Oncol. 2003;39(4):405414. doi:10.1016/S1368-8375(02)00164-1 
73. Nasher AT, Al-Hebshi NN, Al-Moayad EE, Suleiman AM. Viral infection and oral habits as risk factors for oral squamous cell carcinoma in Yemen: a case-control study. Oral Surg Oral Med Oral Pathol Oral Radiol. 2014;118(5):566-572. doi:10.1016/j.oooo.2014.08.005

\section{ACKNOWLEDGEMENTS}

We thank the National Natural Science Foundation of China for supporting this work.

CONFLICTS OF INTEREST

Authors have completed and submitted the ICMJE Form for Disclosure of Potential Conflicts of Interest and none was reported.

\section{FUNDING}

This work is partially supported by the National Natural Science Foundation of China (NSFC 31800114).

PROVENANCE AND PEER REVIEW

Not commissioned; externally peer reviewed. 